\title{
OPORTUNISMO E OS CONTRATOS AGROINDUSTRIAIS: UM ESTUDO DE CASO NO MERCADO ORIZÍCOLA NO SUL DO BRASIL
}

\author{
Opportunism and Agroindustrial Contracts: A Case Study in the Rice Market in the South of Brazil
}

RESUMO

$\mathrm{O}$ artigo examina a presença de oportunismo em contratos agroindustriais estabelecidos entre produtores rurais de arroz e indústrias beneficiadoras do produto no estado do Rio Grande do Sul. Tendo como porto de partida o conceito de governança eficiente, buscou-se compreender e mensurar de que forma o comportamento oportunista dos agentes pode, eventualmente, se manifestar, nas estruturas de governança identificadas, dado o princípio da incompletude contratual. Segundo a teoria, em determinadas estruturas híbridas de governança a via contratual seria uma boa solução para os custos de transação. No entanto, os contratos agroindustriais estariam imunes à ocorrência de ações oportunistas? Do ponto de vista metodológico, o estudo utilizou-se de métodos mistos de investigação. Em linhas gerais, os acordos examinados revelaram baixa ocorrência de comportamento oportunista, elevado grau de confiança entre os agentes e co-especificidades de avaliação e de prova que permitem resguardar a relação de práticas oportunistas.

Mauro Barcellos Sopena

Universidade Federal do Pampa

maurosopena@unipampa.edu.br

Alessandro Porporatti Arbage

Universidade Federal de Santa Maria

aparbage@yahoo.com.br

Recebido em: 26/07/2017. Aprovado em: 16/03/2020.

Avaliado pelo sistema double blind review

Avaliador científico: Elisa Reis Guimarães

DOI: 10.48142/2238-68902019v21n1-3p2035

\begin{abstract}
The article examines the presence of opportunism in agroindustrial contracts established between rural producers of rice and industries that benefit the product in the state of Rio Grande do Sul. Starting from the concept of efficient governance, the aim was to understand and measure the opportunist behavior of the agents may, in the identified governance structures, manifest itself, given the principle of contractual incompleteness. According to the theory, in certain hybrid governance structures the contractual path would be a good solution for transaction costs. However, would agribusiness contracts be immune to opportunistic actions? From the methodological point of view, the study used mixed methods of investigation. In general terms, the agreements examined revealed a low occurrence of opportunistic behavior, a high degree of trust among the agents, and the co-specificities of evaluation and evidence that allow to protect the relation of opportunistic practice.
\end{abstract}

Palavras-chave: Governança. Orizicultura. Nova Economia Institucional.

Keywords: Governance. Rice industry. New Institutional Economy.

\section{INTRODUÇÃO}

O conceito de contrato possibilitou avanços importantes do ponto de vista da compreensão da realidade, especialmente em ambientes agroindustriais. Valendo-se deste avanço conceitual, este trabalho centraliza suas investigações em torno do fenômeno, ou seja, busca caracterizar contratos específicos conduzidos no âmbito da produção de arroz. Analisa-se o funcionamento daqueles contratos, verificando elementos acerca do comportamento oportunista dos agentes envolvidos. Em termos estritamente teóricos, o estudo está amparado no princípio da incompletude contratual, ou seja, na noção de que os contratos elaborados são necessariamente incompletos - muito embora sejam desenhados para arrefecer a ocorrência de ações oportunistas.

A pesquisa desenvolve-se no âmbito da Nova Economia Institucional. Explora o comportamento oportunista dos agentes em formas contratuais desenhadas para o setor agroindustrial orizícola nos municípios de Pelotas e Itaqui, Estado do Rio Grande do Sul. Em termos teóricos, contratos bilaterais possuem propriedades muito bem definidas, tais como: flexibilização, envolvimento e continuidade da relação. Ao contrário, em contratos clássicos, as transações são descontínuas, isoladas e a identidade dos agentes não importa. Contratos neoclássicos distinguem-se 
de forma muito sutil dos bilaterais, embora destoem mais fortemente dos clássicos. Busca-se, especialmente, enfatizar o quanto a especificidade dos ativos condiciona os agentes àquelas práticas contratuais - considerando sua notória centralidade na determinação das estruturas de governança.

Poucas pesquisas se destinam a avaliar o comportamento oportunista com maior propriedade; em verdade, parcela significativa dos escritos científicos está concentrada nas dimensões da transação (especificidade dos ativos, em especial) e nas estruturas de governança concebidas a partir delas (MACNEIL, 1978; ZYLBERSTAJN, 1995; BESANKO, 2006). Esta constatação justifica a condução da presente proposta, ou seja, realça a importância de se conduzir estudos sobre um dos mais importantes pressupostos comportamentais construídos como alternativa ao mainstream e que, em termos gerais, tem sido tratado e compreendido de forma bastante indireta.

Os modelos contratuais oferecidos no âmbito da Nova Economia Institucional (doravante NEI) e, em especial, na economia dos custos de transação - CT (assim como suas interfaces com a economia dos contratos), estão constituídos em bases teóricas institucionais. Apesar das diferentes - e muitas vezes controversas - indicações que o termo instituições possa suscitar, o trabalho de Douglas North é central para a NEI e apresenta, para os pesquisadores da área, o sentido institucional que fundamenta as investigações desta corrente teórica. Em um viés estruturalista de análise, North (1990) compreende que a sociedade possui e impõe regras (instituições) aos indivíduos. De outro lado, os agentes (sejam eles indivíduos ou organizações) praticam suas ações em meio a certas condições institucionais ou mesmo "guiadas" por elas: institutions are the rules of the game in society or, more formally, are the humanly devised constraints that shape human interactions (NORTH, 1990, p. 4).

A definição de contrato, nesta ótica, passa pelo entendimento de que as condições de troca são determinantes do formato da relação contratual (BESANKO et al., 2006. p. 136). A origem desta abordagem teórica se deve, em grande parte, a Coase (1937). Em seu trabalho, intitulado The Nature of the Firm, o questionamento acerca da existência (razão e importância) da firma em um mundo (neoclássico) coordenado via mercado abre caminho para novas interpretações, centralizadas na análise dos custos de transação e, particularmente, no "mundo" dos contratos. Em verdade, Coase não utiliza no referido trabalho a expressão custos de transação, mas exchange transaction (SOPEÑA; ALMEIDA, 2014).
A economia dos contratos rejeita os pressupostos neoclássicos consolidados no chamado paradigma de ArrodDebrew: nesta construção, os contratos são estabelecidos ou formulados por mecanismos de preços e alocação (curva de contrato com ganhos paretianos), noção que carece de sentido real ao ignorar a função da firma contratual (ZYLBERSZTAJN, 2005; MÉNARD, 2014). Contratos são considerados incompletos, especialmente pelo fato de que (a) a capacidade (cognitiva) dos contratantes é limitada e (b) as informações são assimétricas. Especialmente nesta última propriedade contratual é possível identificar uma relação direta com o próprio desempenho da transação, ou seja, um dos agentes pode apresentar comportamento indesejável (fenômeno denominado de risco moral) ou a transação resultar em seleção adversa - não efetivação (ZYLBERSZTAJN, 2005).

Paralelamente aos pressupostos comportamentais desenvolvidos pela NEI, as características ou dimensões das transações referem-se a três elementos específicos; são eles: ativos específicos, incerteza e frequência das transações. Em verdade, a especificidade dos ativos é considerada por Williamson como a dimensão mais importante. A especificidade dos ativos pode variar. Para um elevado nível de especificidade dos ativos, considera-se a hierarquia como forma de governança a ser adotada. Apesar da consolidação dos custos de transação enquanto elemento teórico de análise, a dificuldade de sua mensuração representa, para muitos pesquisadores, uma lacuna desta área de investigação. Importa indicar que Yoram Barzel propôs uma alternativa teórica a esta questão, incorporando a noção de "custos de mensuração" à análise (CALEMAN et al., 2008).

Williamson incorpora três dimensões à transação, ao mesmo tempo em que evidencia o recorte teórico baseado em modelos de governança - formas organizacionais que buscam diminuir CT. Nesta perspectiva, estruturas de governança assumem um sentido mais realista na análise das transações, com aceitação acadêmica. Com respeito às diferentes estruturas de governança e aos CT existentes na realidade agroindustrial, o argumento de Williamson (2013) é objetivo. Para o autor:

Food processors have at least three choices. They can buy in the spot market. They can write contracts with individual farmers (maybe several, possibly many) to deliver a specified amount of product (possibly of a specified quality) at an agreed upon delivery date (maybe several different dates). Or they could integrate backward into farming and produce to their own needs (backward vertical integration). (WILLIAMSON, 2013).

A noção de governança eficiente representa um constructo teórico fundamental desenvolvido por 
Williamson (BROUSSEAU; GLACHANT, 2008). Esta contribuição particular importa na medida em que acopla duas dimensões da transação ao pensamento de Ian MacNeil, formulador da tipologia dos contratos relacionais. Surgem deste exame, três formas de governança: a governança de mercado (associada ao contrato clássico; de curto prazo), a governança trilateral (vinculada aos contratos neoclássicos) e a governança bilateral (promovida a partir de contratos relacionais).

Nestes termos, estruturas (eficientes) de governança utilizam o mercado para contratos clássicos, supondo a baixa especificidade de ativo (independentemente do nível de frequência observado para a transação). Em outro extremo, a hierarquia prevalece como decorrente da alta frequência e especificidade dos ativos (investimentos específicos). Em transações intermediárias, ou seja, reguladas pela via contratual, a especificidade dos ativos não é alta a ponto de determinar a hierarquia e, portanto, contratos neoclássicos (trilaterais) e relacionais (bilaterais) são evidenciados como arranjos eficientes.

Em contratos clássicos não há continuidade da relação, tampouco compromisso forte entre os agentes (faceless). Ao contrário, em contratos neoclássicos, as relações são duradouras e flexíveis por efeito da maior especificidade dos ativos em relacionamento. Em contratos relacionais, frequência e especificidade importam (investimentos idiossincráticos ou idiosyncratic). A sustentação de longo prazo desta relação é desejada.

A discussão sobre oportunismo, neste ambiente contratual, tem origem em especulações acerca da busca do auto-interesse dos agentes (WILLIAMSON, 1985). Este elemento, segundo o autor, varia em intensidade, passando pela obediência (forma fraca de auto-interesse), o auto-interesse simples (semifraca) e o oportunismo (forte) - configuração esta diretamente relacionada aos custos de transação. A busca do auto-interesse com avidez ou dolo é a conceituação central utilizada para demarcar o comportamento oportunista dos agentes (indivíduos que, no caso, possuem menos princípios). Não obstante, formas sutis de fraude são consideradas mais frequentes e próximas à realidade. Oliver Williamson considera as ações de mentir, roubar ou trapacear como formas flagrantes ou reveladas de oportunismo, destacando, porém, que a assimetria de informações é um componente ativo e presente naquelas práticas. A prática oportunista pode ocorrer ex ante contratação (antes de os agentes assinarem um contrato) ou ex post (fase de execução do contrato), casos estes denominados de risco moral (NIESTEN; JOLINK, 2012). Na compreensão destes autores, o oportunismo na NEI somente possui sentido quando percebido em uma relação contratual. O comportamento oportunista dos agentes é um tema de pesquisa importante que necessita de estudos empíricos (LUMINEAU; OLIVEIRA, 2020).

Com referências a Nicholas Georgescu-Roegen e Nicolau Maquiavel, Williamson argumenta que os comportamentos que desviam das regras são naturalmente observados. Os indivíduos possuem fins que não são unicamente relacionados ao acordo em si ou, em outros termos, perseguem fins próprios e reivindicam o que consideram ser possível a eles para além do acordo original. As interpretações orbitam, portanto, a noção de que os indivíduos possuem uma propensão ao comportamento oportunista, pressuposto que elege a formulação de salvaguardas contratuais como elemento importante. Em seu trabalho de 1993, intitulado Opportunism and its Critics, Williamson reforça seus argumentos ao indicar que um tratamento "míope" ou "primitivo" do fenômeno seria aquele de fundo maquiavélico, ou seja, destinado a ações "preventivas" ao oportunismo. Esta não seria a única lição a considerar, considera ainda, que a contratação ingênua não pode ser aventada (WILLIAMSON, 1993).

A Figura 1 organiza quatro casos ou condicionantes contratuais submetidos aos diferentes níveis de oportunismo e racionalidade dos agentes. Williamson procura demonstrar combinações extremas entre utopia e realidade.

Pela exposição, em três casos não surgem problemas contratuais, especialmente no caso 1, considerado pelo autor como utópico. No caso 4, ou seja, quando se assume a racionalidade limitada dos agentes e a presença de oportunismo, dificuldades contratuais são detectadas. A realidade corresponderia a esta perspectiva (WILLIAMSON, 1985).

\begin{tabular}{|c|c|c|c|}
\cline { 3 - 4 } \multicolumn{2}{c|}{} & \multicolumn{2}{c|}{ Condição de Racionalidade Limitada } \\
\cline { 3 - 4 } \multicolumn{2}{c|}{} & Ausente & Presente \\
\hline $\begin{array}{c}\text { Condição de } \\
\text { Oportunismo }\end{array}$ & Ausente & (1) Felicidade & (3) Contratação - Cláusula Geral \\
\cline { 2 - 4 } & Presente & (2) Contratação Abrangente & (4) Dificuldades Contratuais Sérias \\
\hline
\end{tabular}

FIGURA 1 - Pressupostos Comportamentais e Contratação

Fonte: adaptado de Williamson (1985)

Organizações Rurais \& Agroindustriais, Lavras, v. 21, n. 1-3, p. 20-35, 2019 


\section{METODOLOGIA}

A metodologia empregada neste trabalho reveste-se do propósito de analisar a realidade com profundidade e a partir de uma base empírica pré-estabelecida. Assume-se a intenção de examinar a eventualidade do comportamento oportunista presente na conduta dos agentes participantes de contratos agroindustriais do setor orizícola. Categorias de análise são utilizadas com o intuito de avaliar diferentes fontes de custos de transação que, de forma potencial, associam-se ao comportamento oportunista das partes contratantes. Com o objetivo de mensurar o comportamento oportunista existente naquelas transações, recorre-se à lógica Fuzzy de análise, permitindo que um enfoque quantitativo seja empregado paralelamente ao estudo de caso (perspectiva quali-quanti de análise). Entrevistas e coleta de dados documentais foram conduzidas conjuntamente. A adoção de um estudo de caso combinado com a modelagem Fuzzy insere-se em uma inquietante questão: a mensuração e formalização dos conceitos da NEI. O argumento de que estes conceitos carecem de formalização é percebido em muitos escritos. Assim, ao contrário da ("elegância da") Economia Neoclássica, a Economia dos Custos de Transação é "acusada", por alguns autores, de falta de formalismo matemático ou rigor analítico (MARQUES JUNIOR; PORTO JUNIOR, 2003). Embora não se pretenda enfrentar esta questão, objetiva-se indicá-la como existente.

O nível de análise do presente trabalho refere-se à relação contratual formada entre produtor rural (unidade agrícola de produção) e processador de alimentos (unidade industrial). No plano quantitativo, elegem-se três categorias de análise como forma de interpretar o comportamento dos agentes, assim como subdivisões específicas a cada caso. O Quadro 1 apresenta as seguintes categorias: confiança, referências e precaução. A primeira categoria de análise utilizada nesta pesquisa - confiança - foi proposta anteriormente em trabalho de Reys et al. (2010). Para aqueles autores, a possibilidade de avaliação quantitativa (mensuração) de fontes de custos de transação - como no caso do comportamento oportunista, é possível e desejável por meio da abordagem fuzzy. A categoria denominada referências é aqui utilizada como meio de analisar de que forma o agente entrevistado observa os demais agentes em seu ambiente negocial. Trata-se, portanto, de uma categoria mais abrangente que, ao ser proposta para o conjunto analítico, permite trazer a visão do entrevistado acerca dos contratos realizados paralelamente ao seu. Por fim, a importância dada pelos agentes à precaução ou salvaguardas, elementos estes notórios na formação de contratos, objetiva fixar o entendimento dos agentes quanto a possibilidade de que cláusulas sejam violadas.

QUADRO 1 - Comportamento oportunista dos agentes - categorias de análise da pesquisa

\begin{tabular}{cc}
\hline Categorias de Análise & Elementos de investigação empírica \\
\hline Confiança & $\cdot$ Histórico da relação comercial \\
& $\cdot$ Expectativas quanto ao pleno \\
cumprimento do contrato \\
$\cdot$ Referências profissionais dos \\
Referências & agentes (reputação externa) \\
& Acompanhamento de outras \\
& transações (indicativos) \\
Precaução & salvaguardas e garantias contratuais \\
& $\cdot$ Importância da existência de \\
projetos alternativos/substitutos
\end{tabular}

Fonte: elaboração do autor

Organiza-se, para cada categoria analítica, dois elementos principais. A exploração destes elementos, seja por meio de entrevistas abertas ou por escala de medida, permite, nos dois primeiros casos, que o entrevistado responda as questões a partir de sua própria experiência sobre o comportamento do outro contratante. Assim, produtores rurais foram indagados acerca da agroindústria/processador e estes, sobre os primeiros. A terceira categoria de análise opera no sentido de apurar a importância que o agente dá à precaução. A categoria confiança foi analisada por meio do histórico da relação existente entre as partes contratantes e pela expectativa de cada parte quanto ao cumprimento contratual pleno. Por referências, entende-se a percepção do agente a respeito do comportamento da outra parte com seus pares - reputação externa. Por fim, adotou-se o termo precaução para designar o quanto cada parte considera importante proteger-se do risco de oportunismo. Presume-se, nesta questão, que quanto maior for a expectativa do agente sobre a ocorrência de oportunismo, maior também será a importância dada às salvaguardas ou projetos alternativos àquele original.

Após o processo de coleta dos dados, adiante apresentado, a síntese cruzada dos casos passa a importar na medida da estrutura comparativa (YIN, 2010). A utilização de métodos mistos de investigação ocorre quando a combinação de métodos qualitativos e quantitativos está presente na interpretação do fenômeno. Esta combinação 
é válida para uma ampla variedade de estudos e melhor aplicada quando visa a complementariedade das fontes de dados e emprego teórico (CRESWELL; CLARK, 2013). Este trabalho utilizou, para tanto, o que os autores acima citados definem como métodos mistos fixos, ou seja, definidos ex ante coleta de dados. Neste sentido, questões abertas, somadas à observação direta $\mathrm{e}$ análise documental (contratos formais) representaram o componente qualitativo do estudo. Questões fechadas, com interpretação baseada na abordagem Fuzzy, englobaram a abordagem quantitativa. Especificamente quanto à análise documental, considera-se importante atentar para a ideia de que, no mundo real, muitas atividades e fenômenos estão propensos a algum tipo de registro (FLICK, 2009). Segundo Prior (apud FLICK, 2009) e Poupart (2010), é necessário olhar para o fato de que documentos estão sempre vinculados a uma realidade ou ação.

O emprego da abordagem quantitativa justifica-se pela intenção de mensurar elementos da pesquisa relativos ao comportamento oportunista. A lógica Fuzzy caracterizase como uma ferramenta quantitativa adequada para este fim, sobretudo por sua capacidade de analisar questões vagas ou imprecisas (VELLASCO, 1999) decorrentes de respostas com estas características (variáveis linguísticas) que são características do pensamento humano (BARIN, et al., 2010). Em alternativa à teoria convencional, que determina se um elemento $x$ pertence ou não a determinado conjunto ou classe ( $x \in \mathrm{A}$ ou $x \notin \mathrm{A})$, conjuntos Fuzzy permitem modelar certos fenômenos com maior aproximação e relativização (graus), obtendo resultados multivalorados que melhor aproximam-se da realidade (MARRO, 2010). A pertinência em conjuntos fuzzy, portanto, trata-se de um conceito fundamental. O tratamento de uma variável linguística em modelos fuzzy possui valor qualitativo próprio (seu termo linguístico particular) e quantitativo pela noção de pertinência expressa por uma função (MAGNAGO, 2005). Na lógica Fuzzy, graus de pertinência (verdade ou "verdade parcial") são admitidos e os elementos podem pertencer a mais de uma classe - noção implícita de parcialidade (GOMIDE et al., 1995; ORTEGA, 2001; AMENDOLA, et al., 2004).

Conjuntos clássicos ou binários (Equação 1 com condição bivalente) não apresentam os graus de pertinência $\mu(\mathrm{x})$ indicados na Equação 2. Resultados em conjuntos clássicos, portanto, caracterizam por serem extremos; como nos exemplos: verdadeiro/falso, ligado/desligado e sim/não. Ao contrário, em conjuntos fuzzy, resultados extremos podem ocorrer, porém, não exclusivamente. A seguir as equações: $f(x)=\{1$ se,e somentese, $x \in A$ 0 se,e somentese, $x \notin A$ (1)

$\mu(x)=\{1$ se, esomentese, $x \in A 0$

se,esomentese,

$x \notin A \quad 0 \leq \mu(x) \leq 1 \forall x \mid x$ parcialmenteem $A$

A teoria clássica, portanto, assume que $f(x): U \rightarrow$ $\{0,1\}$, ou seja, somente 0 ou 1 . O grau de pertinência $\mu_{A}(x)$ para a abordagem fuzzy está representado na Equação 3 abaixo. Nela, o intervalo de pertinência $[0,1]$ indica que, quando $0, \mathrm{x} \notin \mathrm{A}$; quando $1, \mathrm{x} \in \mathrm{A} \mathrm{e}, \mathrm{em}$ complemento, valores entre 0 e 1 representam a noção de parcialidade. A função de pertinência implica, portanto, resolver (escolher) em determinado universo de respostas $U$, um conjunto fuzzy $A$ definido por regras determinantes da pertinência de cada elemento para valores do intervalo [0,1] (OLIVEIRA, 2014) - conforme indicado na Equação 3:

$\mu_{A}: U \rightarrow[0,1]$.

O sistema Mamdani de análise dos dados, empregado neste estudo, utiliza o operador mínimo para valores de entrada e o operador máximo para a agregação das regras (REYS, et al, 2011). Nele, além da fuzzyficação e adoção de regras fuzzy, emprega-se o processo de defuzzyficação na determinação dos resultados numéricos da pesquisa. Assim, tem-se que: (a) fuzzyficação: determinação da função de pertinência, estabelecimento de regras (IF, $A N D$, OR e THEN) e conjuntos fuzzy decorrentes. Conjuntos crisp são aqui transformados no sentido nebuloso, ou seja, com definição de fronteiras graduais (OLIVEIRA, 2014). (b) defuzzyficação: resultado ou saída numérica por meio da técnica centróide $\left(\mathrm{C}_{\mathrm{OG}}\right)$, baseada na noção de centro de gravidade, massa ou área $(\mathrm{CA})$ - para a região própria do conjunto fuzzy. A defuzzyficação (Equação 4 abaixo) é representada como segue (MARRO, 2009, p. 11). Note-se que o resultado pode ser compreendido como uma média ponderada na Equação 4:

$C_{O G}=\frac{\sum_{x=a}^{b} \mu(x) \cdot x}{\sum_{x=a}^{b} \mu(x)}$

A técnica centróide parte, assim, da noção de centro de gravidade da física, ou de equilíbrio (ORTEGA, 2001). Nesta perspectiva, conforme Oliveira (2014), parâmetros são importantes na determinação da função de pertinência, 
especialmente pelo fato de que deles decorrem funções do tipo trapezoidal (quatro parâmetros), triangular (três parâmetros), entre outras funções de menor frequência na literatura. Assim, além das funções triangular e trapézio, outras funções de pertinência são utilizadas. A escolha de tais funções depende diretamente do objeto de estudo. Na presente pesquisa, cada variável de entrada $x$ (medida pelas categorias de análise confiança, referências, precaução) gerou inferências para a variável de saída $y$ (comportamento oportunista). No caso específico:

A partir das anotações anteriores, sentenças do tipo "IF $x$, THEN y", denominadas de regras, foram definidas.

$y=f(x 1, x 2, x 3)$

Sendo x o elemento precedente e y, o consequente, e partindo das três categorias de análise do trabalho, a matriz composta por 27 regras $^{1}$ foi estabelecida. As respostas obtidas, no intervalo de 0 a 10 , foram submetidas aos diferentes graus de pertinência. Os parâmetros para fuzzyficação foram dispostos na função trapezoidal, ou seja, com quatro parâmetros determinados. A escolha da função trapezoidal se deveu, sobretudo, ao fato de que um intervalo de valores pode assumir um grau de "verdade" unitário, ou seja, com pertinência igual a 1. Posselt (2014, p. 30) caracteriza com propriedade esta peculiaridade da função: uma das características de uma função trapezoidal é o fato de um intervalo de valores assumirem a possibilidade de veracidade de $100 \%$. Os parâmetros utilizados no modelo foram os seguintes: - Confiança, Referências e Precaução (0 a 10 valor atribuído). Baixa - Rampa Esquerda (0, 3, 4,5); media - Trapézio (3, 4,5, $5,5,7)$ e alta - Rampa Direita $(5,5,7,10)^{2}$.

\section{RESULTADOS E DISCUSSÃO}

$\mathrm{O}$ estudo de caso refere-se à relação contratual estabelecida entre a agroindústria JOSAPAR (Joaquim Oliveira S/A Participações) e os produtores de arroz que com ela transacionam sua produção. A pesquisa foi realizada no município de Pelotas, Região Sul do Estado do Rio Grande do Sul, onde a indústria está sediada.

${ }^{1}$ Considerando as três variáveis e suas decorrentes combinações (33), 27 regras foram geradas.

${ }^{2}$ Quanto à variável de saída, os seguintes parâmetros foram adotados: Comportamento Oportunista (0 a 10 valor atribuído). Muito_baixo - Rampa Esquerda $(0,1,5,2,5)$; baixo - Trapézio $(1,5,2,5,3,5,4,5)$; medio - Trapézio (3,5 , 4,5 , 5,5 , 6,5); elevado - Trapézio (5,5 , 6,5 , 7,5 , 8,5); muito_elevado - Rampa Direita $(7,5,8,5,10)$. A operacionalização destas regras difere para cada questão de pesquisa.
Paralelamente, estudos foram conduzidos junto à outra importante unidade industrial da Josapar, situada no Município de Itaqui - Região da Fronteira Oeste do Estado. A coleta de dados, realizada no ano de 2016, concentrouse, portanto, em importante transação estabelecida pela JOSAPAR: a compra de arroz para beneficiamento.

A indústria JOSAPAR é uma Companhia Aberta (Ações: JOPA3 - Josapar ONJOPA4-Josapar PN), presente no mercado há 95 anos. Opera com produtos alimentícios de expressiva representatividade no âmbito nacional, tendo o arroz Tio João como sua principal marca. O conjunto de produtos é também representativo em termos de exportação, atingindo mais de 40 países. Com produção de mais de 450 mil toneladas de arroz/ano, a indústria realiza transações expressivas com produtores da região pertencentes ao setor arrozeiro (JOSAPAR, 2015). Registros do Instituto Riograndense do Arroz (IRGA) indicam a JOSAPAR como segunda maior indústria de beneficiamento de arroz do estado gaúcho no ano de 2014. Dados documentais da Associação dos Arrozeiros de Pelotas, Turuçu e Capão do Leão apontam a região como o maior centro de processamento de arroz do território nacional. Nela, cerca de 50 arrozeiros são responsáveis pelo cultivo de 17 mil hectares.

O produtor de arroz é um dos principais agentes do setor. Através dele, o cultivo é realizado em terras de várzea, ou seja, o arroz de plantio irrigado é cultivado em áreas planas para que seja possível a permanência de água em todo o processo de plantio direto. Esta é, portanto, uma característica produtiva do setor que não pode ser desconsiderada. Segundo Costa Júnior (2014, p. 14), o plantio direto do produto em "terras altas", ou seja, em sistema alternativo àquele utilizado em solos de várzea, não se mostra competitivo, tampouco de alta produtividade: (...) há indícios de que o arroz de terras altas não é adaptado a cultivo sob sistema de plantio direto, ao contrário do arroz irrigado por inundação, em que o sistema já é amplamente utilizado e com bastante sucesso. Esta consideração, apesar de suscitar a ideia de que o uso de terras de várzea represente um ativo específico em relacionamento para os agentes, não foi assim considerada; ao menos por duas razões: (a) os agentes não apontaram esta especificidade na descrição do relacionamento com a indústria e, de outro lado, (b) tal sistema produtivo já é tradicional e preponderante na atividade orizícola daquela região - o que indica muito mais a existência de uma "característica produtiva regional própria” do que um investimento particularmente realizado para sustentar a transação (ativo específico).

$\mathrm{O}$ arrendamento ou propriedade da terra, a estrutura produtiva empregada (especialmente armazenagem 
e secagem), os recursos financeiros e os processos tecnológicos disponibilizados são determinantes para o desempenho da produção. O processo de negociação da produção com a indústria ou com o corretor se pauta por tais circunstâncias, notadamente quando o conjunto de recursos utilizados permite o armazenamento para negociações futuras. A transação de compra e venda do produto é estabelecida por um dos seguintes casos: (a) produtor e indústria; (b) produtor e corretor e (c) corretor e indústria.

\subsection{Elementos da Relação Contratual}

O contrato estabelecido na transação de compra e venda de arroz apresenta elementos mínimos de formalidade. As negociações realizam-se em moldes padronizados, com contatos diretos entre compradores e vendedores. $\mathrm{O}$ entendimento acerca das propriedades do produto é realizado pelos agentes por meio de acertos informais e instantâneos. Não foi detectado no trabalho de campo a presença de ativos específicos em relacionamento, tampouco o registro de significativa frequência das transações. Estas observações iniciais sugerem a existência de um contrato clássico. A padronização percebida exclui ainda elementos de continuidade da relação, próprios de contratos relacionais. Em adição, não há razão para sugerir a flexibilidade ou relações de longo prazo entre os agentes. A transação é realizada de forma objetiva.

Entrevistas com corretores de arroz atuantes no município revelaram informações que corroboram os argumentos anteriores. Em um dos depoimentos, um corretor com trinta anos de atuação no mercado de arroz apontou as seguintes características para o setor: (a) o produto e a negociação são altamente padronizados. As partes conhecem plenamente as características do produto que negociam e a classificação do produto raramente é questionada. A qualidade do produto é o elemento que interessa na negociação. (b) O pagamento é sempre a vista (normalmente dentro de 48 horas, no máximo de 72 horas após o acerto), com depósito direto na conta corrente do produtor. Não há no ramo problemas quanto ao pagamento. (c) Os negócios são firmados por e-mail, sem contrato ou documento relativo ao acordo. O pagamento pela corretagem é padrão, $1 \%$ do volume comercializado, e o documento utilizado na transação é a nota fiscal. Para outra corretora, considerada pelos produtores entrevistados como a mais competente da região para realizar negociações de compra e venda, as transações não requerem formalidades especiais. Com relação à forma de contratar, revela que:
Eu hoje faço negócios por e-mail e até por WhatsApp, direto com arrozeiros e indústria; eles todos já têm o aplicativo. O único documento que uso é esse contrato simbólico só, que nem tem valor jurídico; tem valor jurídico nulo. É interessante né, quando a gente vai numa loja comprar, pedem CPF, documentos, consulta ao SERASA; mas, para comprar 100 mil sacos de arroz, negócios que são com grandes volumes de dinheiro, basta um telefonema (entrevista com a corretora de arroz).

No referido contrato, abaixo reproduzido no Quadro 2, as informações são gerais, sintéticas e objetivas. Os itens compreendem o tipo de operação que está sendo executada, a especificação técnica, as condições de pagamento, os dados de cada parte e o transporte do produto.

Além da compra direta do produto, negócios de importação/exportação fazem parte do trabalho de corretagem. Depósito e liquidação correspondem respectivamente à entrega do produto à indústria (com pagamento de taxa sobre o volume depositado) e, para o caso de liquidação, a venda do produto já depositado à indústria possuidora da guarda do arroz (descontados os $8 \%$ do depósito). O depósito, portanto, pode ser considerado como uma pré-venda, uma vez que há o pagamento pela guarda, o transporte (custo de expedição) e o tratamento do produto feito pela indústria via nota de depósito com índices técnicos. No caso de acordo entre as partes, basta o produtor "liquidar" o produto e realizar o acerto com a indústria ${ }^{3}$.

Alguns acordos comerciais, realizados diretamente entre produtores e Josapar, destoam das características antes mencionadas. Relações específicas entre a indústria e arrozeiros da região foram detectadas no estudo e demonstram que, em alguma medida, especialmente para pequenos produtores, a Josapar conduz a produção de arroz por meio de financiamento. Nestes casos pontuais, um "embrião" de sistema integrado de produção é verificado, sobretudo quando o fornecimento de insumos e assistência técnica soma-se ao financiamento dado ao produtor:

Em alguns casos, funciona como um banco: a Josapar financia o pequeno produtor, dá insumos e assistência técnica. Isso começou porque queríamos que o produtor produzisse as variedades 409 e 417 , mas com o tempo, isso se perdeu, especialmente porque a produtividade era baixa. Essas variedades eram importantes porque observamos,

\footnotetext{
${ }^{3}$ Para os agentes do setor, a liquidação não é considerada ou entendida como venda, dado que o produto já se encontra na indústria. A venda de arroz se caracteriza tão somente quando o acordo é fechado, o carregamento é acertado e a entrega efetuada diretamente à indústria.
} 
naquela época, uma tendência forte de mercado para esse tipo de arroz. Atualmente, ainda existe esse sistema, mas não mais só para aquelas variedades. É uma opção que a Josapar oferece para quem quiser (Gerente da Josapar).

A análise conjunta das informações não permite indicar o financiamento realizado pela Josapar como uma tendência de integração para o setor, tampouco como uma modalidade concorrente de transação. Por outro lado, o fenômeno acentua-se somente na unidade industrial de Itaqui, sendo que na unidade de Pelotas não se mostra expressivo ${ }^{4}$.

\subsection{Comportamento Oportunista dos Agentes}

O risco relativo ao comportamento oportunista centraliza-se em dois elementos fundamentais: a classificação do produto e o pagamento. Tais elementos apresentam-se como potenciais canais para práticas ilícitas, muito embora a presença de ações oportunistas entre os agentes seja ínfima. A transação de compra e venda do arroz apresenta-se com alto nível de padronização. Para os agentes, os baixos custos de mensuração concorrem para inibir o comportamento oportunista, sobretudo quando o nível de informação acerca das negociações é elevado para ambas as partes contratantes.

QUADRO 2 - Contrato de compra e venda - corretora de arroz

\begin{tabular}{|c|c|c|}
\hline \multicolumn{3}{|c|}{ CORRETORA } \\
\hline No. 2756 & Contrato Compra e Venda de Arroz & Data: 07/05/2015 \\
\hline \multicolumn{3}{|c|}{ TIPO OPERAÇÃO } \\
\hline COMPRA $(\mathrm{X})$ & DEPÓSITO ( ) $\quad$ LIQUIDAÇÃO ( ) & IMPORTAÇÃO ( ) \\
\hline \multicolumn{3}{|c|}{$\begin{array}{l}\text { Vendedor: xxxxxxxxxx xxxxx. Endereço Lavoura: xxxxx xxxxx, xx. Município: Santa Vitória do Palmar } \\
\text { CNPJ / CPF: xxx.xxx.xxx-Xx. Inscrição Estadual: xxx/xxx.xxx-x. CEI: xx.xxx.xxxxx/xx } \\
\text { Comprador: xxx x xxx. Endereço: xxxxxxx xx xxxxx, xx. Município: Pelotas } \\
\text { CNPJ / CPF: xxx.xxx.xxx-xx. Inscrição Estadual: xxx/xxx.xxx-x } \\
\text { Pelo presente contrato comercial, fornecedor e adquirente acima mencionados, firmam entre si, o seguinte: } \\
\text { Produto: arroz. Variedade: GURI. Quantidade: } 2.000 \text { SCS (3 carretas). Valor (sacos } 50 \mathrm{Kg}): 36,50 \text { (posto) }\end{array}$} \\
\hline \multicolumn{3}{|c|}{ ESPECIFICAÇÃO DO PRODUTO } \\
\hline $\begin{array}{l}\text { Rendimento: } 68 \\
\text { Inteiro: } 60 \\
\text { Quebrado: } 08 \\
\text { Impureza (\%): } 00\end{array}$ & 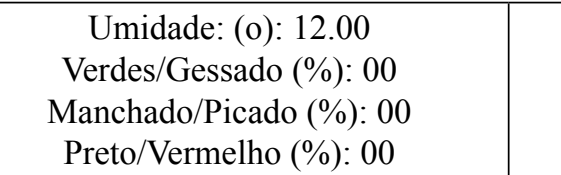 & $\begin{array}{c}\text { Amarelo (\%): } 00 \\
\text { Descascado (\%): } 00 \\
\text { Outros (\%): } 00 \\
\text { Secagem (\%): } 00\end{array}$ \\
\hline \multicolumn{3}{|c|}{ CONDIÇÃO DE PAGAMENTO } \\
\hline \multicolumn{3}{|c|}{ Pagamento após descarga: 18/05 R R \$ 71.711,55 e 18/05 R R \$11.024,17 } \\
\hline \multicolumn{3}{|c|}{ BANCO PARA PAGAMENTO } \\
\hline \multicolumn{3}{|c|}{$\begin{array}{cc}\text { Banco: } 001-\text { Banco do Brasil } & \text { Agência: xxxx-x } \\
\text { Favorecido: xxxxxx xxxxxx xxxxx } & \text { Conta Corrente: xx.xxx-x } \\
\text { CNPJ / CPF: xxx.xxx.xxx-xx }\end{array}$} \\
\hline \multicolumn{3}{|c|}{ DADOS DO TRANSPORTE } \\
\hline \multicolumn{3}{|c|}{$\begin{array}{l}\text { Frete: Por Conta Vendedor. Local Carregamento: Santa Vitória. Observação: entrega imediata } \\
\text { Emitir NFs à depósito no valor de R\$ 0,7300 Kg. }\end{array}$} \\
\hline FORI & ADQUIRENTE & CORRETOR \\
\hline
\end{tabular}

Fonte: dados da pesquisa. Nota: alguns dados do contrato foram suprimidos

${ }^{4} \mathrm{O}$ conjunto de dados coletados na pesquisa de campo não indica a integração produtiva como significativa e, mesmo nos casos em que o entrevistado observa o fenômeno, não demonstra intenção de depurá-lo. Ademais, nos poucos apontamentos percebidos sobre o tema, produtores assinalam a possibilidade de integração como uma ameaça ao setor, uma "escravidão branca". Neste sentido, a análise seguinte sobre o comportamento oportunista dos agentes está embasada nas modalidades padronizadas antes referidas.

Organizações Rurais \& Agroindustriais, Lavras, v. 21, n. 1-3, p. 20-35, 2019 


\subsubsection{Percepção da Indústria JOSAPAR}

A aplicação dos instrumentos de pesquisa junto à agroindústria revelou níveis elevados de confiança. As referências que a Josapar possui dos produtores, do mesmo modo, em geral, são positivas. Com relação às salvaguardas, somente em casos de financiamento mostram-se altas. Nos demais casos, ou seja, em modalidades tradicionais de negociação (compra, depósito e liquidação), as salvaguardas praticamente inexistem.

Em entrevista realizada com o gerente de recursos humanos e assuntos jurídicos da Josapar em Pelotas (PA 1), o histórico de negócios junto aos produtores é positivo e isento de práticas irregulares ou conflitos. A expectativa com relação às transações em curso e àquelas a serem firmadas é igualmente positiva. Para o representante da indústria, o trabalho em torno das questões legais é contínuo, mas sem registros expressivos que mereçam destaque: faço parte de um grupo de gestores que trata de questões jurídicas, acompanha os negócios da Companhia (...) mas não temos questões de grandes conflitos não, nada de mais (...) são de acompanhamento. $\mathrm{O}$ entrevistado aponta que o mercado de arroz da região não apresenta conflitos ou irregularidades. Nestes termos, a importância de salvaguardas ou precauções carece de sentido. Para o colaborador, pela natureza da transação, os negócios são executados rotineiramente por intermédio de contratos simples, de compra e venda, sejam eles por meio de depósito, liquidação ou venda direta. Assim, garantias são desnecessárias, uma vez que se pode confiar plenamente na forma com que são realizados os acordos no setor.

Com relação ao método de classificação do arroz recebido e as decorrentes possibilidades de fraude, o dirigente afastou qualquer registro de conflito junto aos produtores. Em seu entendimento, divergências são raras e, se ocorrerem, podem ser brevemente resolvidas através do engenho de prova da indústria ou do produtor. $\mathrm{O}$ engenho de prova, também chamado pelos arrozeiros de mini engenho, trata-se de um equipamento especialmente utilizado para testar ou simular a qualidade e rentabilidade do arroz entregue para beneficiamento. A partir de uma amostra do arroz entregue à indústria, simula-se o beneficiamento como forma de detectar a qualidade do arroz e, portanto, sua classificação e valor comercial. A utilização do referido equipamento está disseminada entre produtores e indústrias, o que permite a rápida dissolução de conflitos que eventualmente possam surgir.

Ausência de irregularidades quanto ao pagamento e entrega do produto foram detectadas junto ao entrevistado. Não há, em seu juízo, comportamento oportunista quanto à forma de pagamento, tampouco quanto à entrega do produto à indústria. Também neste quesito, não há garantias ou salvaguardas estabelecidas. A adoção de salvaguardas e garantias nos negócios firmados com os arrozeiros eleva-se, entretanto, nos casos em que o financiamento ao produtor é estabelecido. Para a Josapar, o fornecimento de recursos financeiros, insumos e assistência técnica requerem garantias extras, formais e de valor jurídico definido. Nestes casos, conforme informado pelo entrevistado, a Josapar recorre aos seguintes instrumentos: garantia de imóvel ou propriedade (campo), avalista e cédula de produtor rural (CPR). Resultados muito próximos foram alcançados em entrevista com o agente da unidade industrial de Itaqui (PA 2). Para o colaborador daquela unidade, a formalidade não é uma característica daqueles contratos, mesmo quando o financiamento dado pela Josapar ao produtor está presente. Quanto a classificação do produto, argumenta:

O produto entregue é sempre analisado a partir de uma amostra. Usamos o calador, que é um aparelho que tira a amostra em diferentes pontos da carga. Depois a gente manda para o pessoal que classifica, eles usam o engenho de prova na análise [...]. Eu sei de casos que já aconteceram tentativas de enganar, mas isso faz tempo. Sei que na Camil já tentaram empurrar Puitá como se fosse 409 ou 417, mas aqui nunca acontece (entrevista com o Gerente da Josapar Itaqui).

O depoimento reforça o que antes fora apresentado na análise referente à unidade industrial de Pelotas. De outro lado, alguns pontos observados na unidade de Itaqui diferem daqueles percebidos na unidade pelotense. A entrevista com o representante de Itaqui permitiu revelar naquela região dois pontos fundamentais: (a) que existe uma maior proximidade relacional com os produtores do que em Pelotas e (b) que aproximadamente $60 \%$ da comercialização ocorre pela via do financiamento (em Pelotas o financiamento existe, porém, é baixo). Ademais, como sugere o entrevistado, existe uma maior tendência à integração na região da fronteira oeste: de tudo que se produz, o financiamento já chega a uns 60\% aqui em Itaqui (...) dá para pensar que caminha sim para a integração, pois, of inanciamento é uma coisa dificil pra eles [arrozeiros] e nós aqui oferecemos. Um elemento que interfere nestas tendências trata-se do tipo de arroz produzido. Enquanto em Pelotas a produção de arroz parboilizado é representativa, em Itaqui outras variedades estão presentes, especialmente aquelas consideradas superiores ou nobres em termos de qualidade e rendimento.

Pelo exposto, não há divergências notórias no caso de Itaqui. Os condicionantes transacionais e o modelo contratual empregado não diferem, em essência, do formato negocial 
estabelecido na unidade principal. O Quadro 3 reproduz o contrato utilizado naquela unidade, idêntico para todas as demais. A pesquisa documental conduzida na pesquisa de campo permitiu verificar que o formato contratual utilizado é simples e contém apenas elementos objetivos daquelas transações. A reprodução abaixo é fiel ao conteúdo do documento original.

QUADRO 3 - Contrato de compra e venda - Josapar Unidade Itaqui

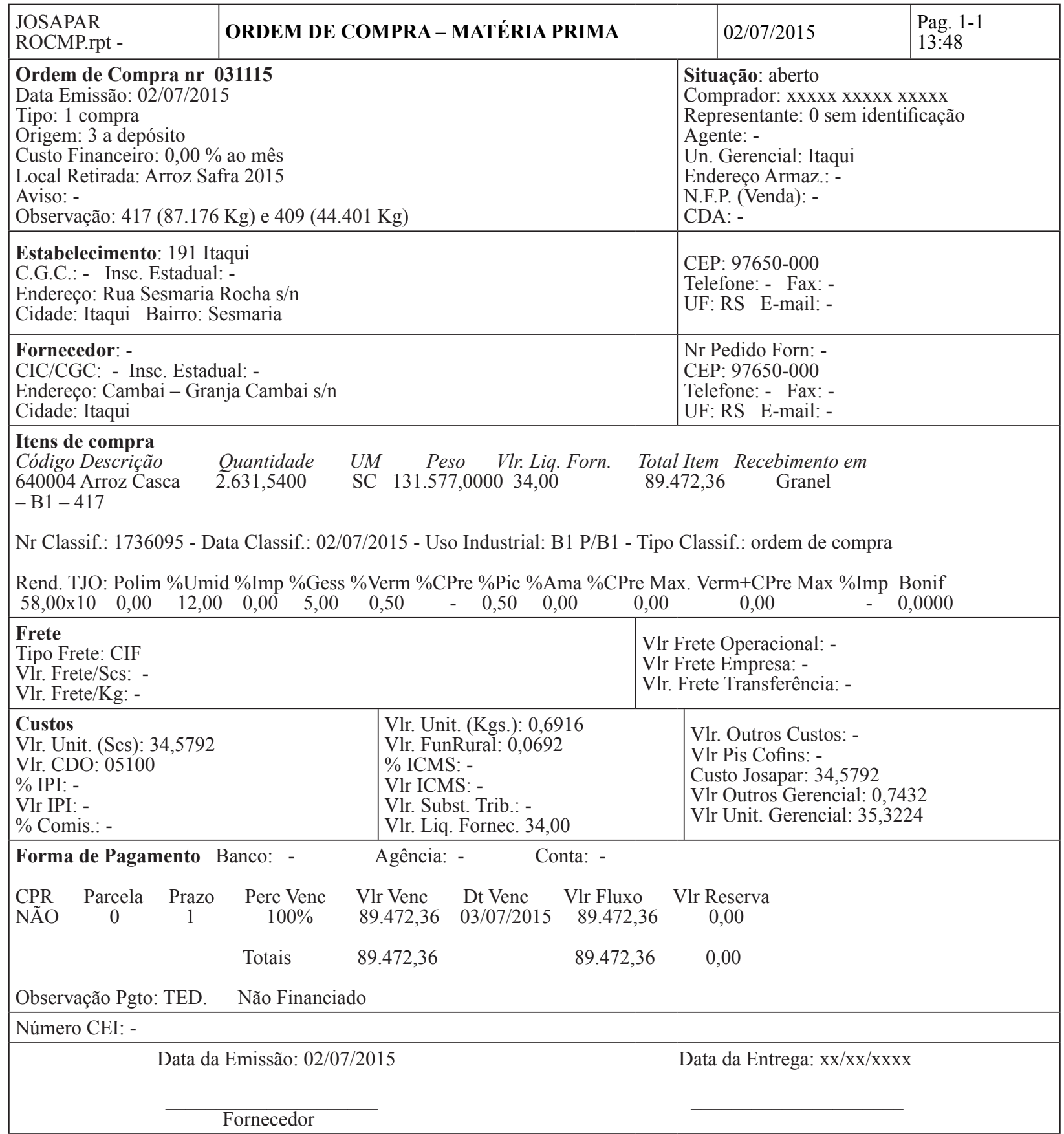

Fonte: dados da pesquisa. Nota: alguns dados do contrato foram suprimidos

Organizações Rurais \& Agroindustriais, Lavras, v. 21, n. 1-3, p. 20-35, 2019 
Entre os valores constantes no documento, é possível verificar o montante pago ao produtor na transação: $\mathrm{R} \$ 89.472,36$. A importância é produto da quantidade negociada de sacas $(2.631,54)$ multiplicada pelo valor pago por unidade na data do acerto $(\mathrm{R} \$ 34,00)^{5}$. Pelos elementos expressos no documento, quatro grandes grupos são destacados: (a) dados gerais da negociação, (b) informações gerais sobre as partes contratantes, (c) características do produto negociado, no caso arroz em casca B1 - 417 consta como predominante e, por fim (d) preços acertados (o que inclui a modalidade de frete e formas de pagamento). Também é possível observar o nome "Ordem de Compra" dado ao documento do acerto, diferentemente da denominação "contrato de compra e venda de arroz", utilizada por corretores. Importa destacar que o documento obtido é padrão, ou seja, é utilizado tanto nos casos de financiamento como nas demais modalidades.
No primeiro caso, soma-se à Ordem de Compra a CPR, garantia esta também instituída na unidade de Pelotas. O uso de avalistas, bens e propriedades como garantia é um instrumento igualmente observado na unidade.

A escala do modelo fuzzy, a partir dos dados coletados, estabeleceu as saídas fuzzy abaixo indicadas na Tabela 1. Com base na operação das categorias e na interpretação dos representantes da indústria, o comportamento oportunista dos produtores de arroz revela-se muito baixo.

Os resultados obtidos são elucidativos e corroboram a análise elaborada no plano qualitativo. Altos níveis de confiança, referências positivas e baixos índices de precaução produzem, através da análise $f u z z y$, resultados muito baixos em termos de comportamento oportunista. A representação gráfica da Figura 2 apresenta o conjunto fuzzy obtido para a primeira sequência de dados, a partir da interpretação do processador de alimentos.

TABELA 1 - Valores atribuídos às diferentes categorias - visão do processador

\begin{tabular}{cccccc}
\hline Tipo & Confiança & Referências & Precaução & Saídas Fuzzy & Comportamento Oportunista \\
\hline \multirow{2}{*}{ PA 1} & 10,00 & 10,00 & 0,80 & 0,995 & Muito Baixo \\
& 10,00 & 9,60 & 3,40 & 1,051 & Muito Baixo \\
\multirow{2}{*}{ PA 2} & 10,00 & 8,90 & 0,30 & 0,995 & Muito Baixo \\
& 10,00 & 9,70 & 0,20 & 0,995 & Muito Baixo \\
\hline
\end{tabular}

Fonte: dados primários da pesquisa

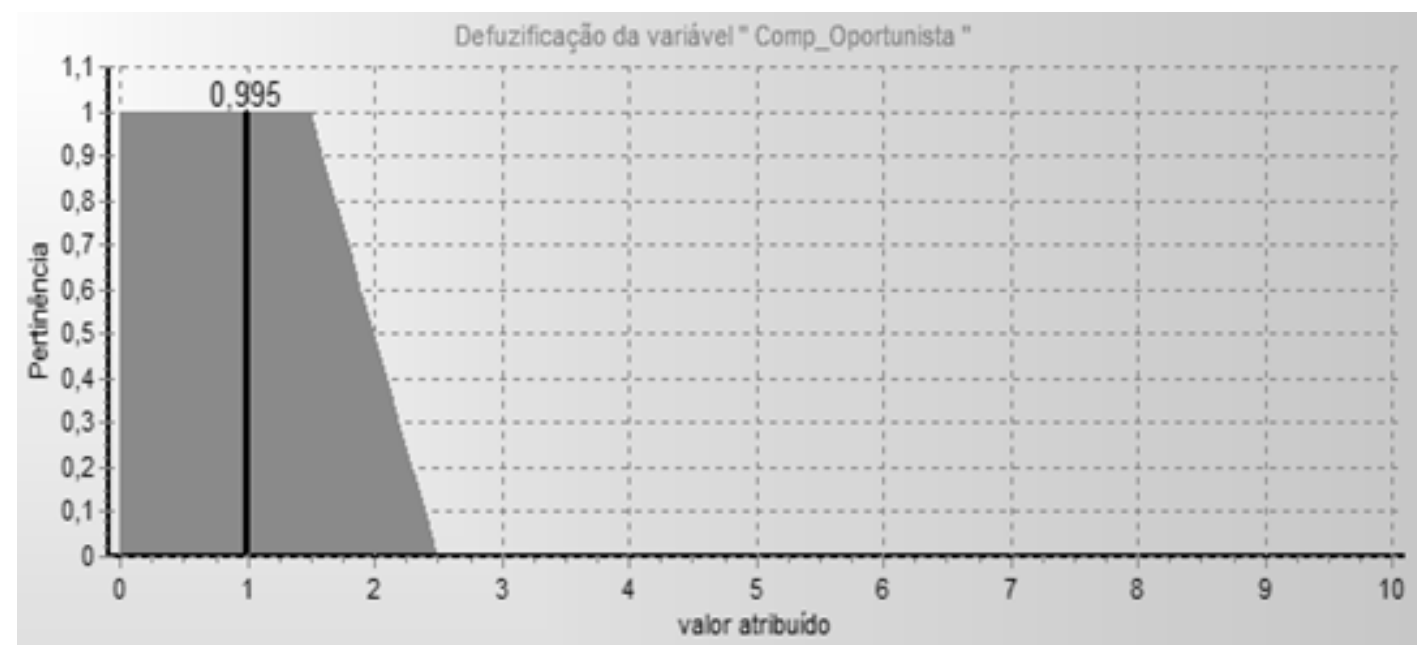

FIGURA 2 - Conjunto Fuzzy: PA Arroz - primeira sequência de dados

Fonte: dados da pesquisa

${ }^{5}$ Série histórica divulgada pela CEPEA/ESALQ indica preço praticado de $\mathrm{R} \$ 33,62$ por saca de $50 \mathrm{~kg}$ (tipo 1) para a região na mesma data do demonstrativo $(1,12 \%$ inferior ao preço pago pela Josapar)

Organizações Rurais \& Agroindustriais, Lavras, v. 21, n. 1-3, p. 20-35, 2019 
A defuzzyficação por centróide resultou em um nível muito baixo de comportamento oportunista. Assim, sugere que, na visão do processador de alimentos, o produtor rural não apresenta comportamento oportunista significativo. Resultado muito semelhante pode ser observado na Figura 3 abaixo $^{6}$ :

Depreende-se, portanto, que os dados obtidos na indústria são uniformes e indicativos de uma ínfima tendência ao oportunismo por parte dos arrozeiros que com ela negociam seu produto. Do mesmo modo, como elucidado na seção seguinte, a percepção dos produtores isenta a indústria de ações oportunistas que possam ser amparadas pela análise.

\subsubsection{Percepção dos Produtores de Arroz}

O trabalho de coleta de dados com produtores revelou informações semelhantes àquelas obtidas junto à indústria. O nível de confiança dos produtores na indústria é muito elevado, assim como as referências que dela possuem. A adoção de salvaguardas e garantias mostrase igualmente baixa. Para um dos entrevistados, práticas ilícitas encontrariam formas de se estabelecerem por meio da classificação irregular do produto ou por meio do não pagamento do acerto: o que se olha sempre é a classificação do produto (...) pode acontecer da classificação ser diferente, quando a classificação é feita na marreta ou na marretinha, como a gente diz ${ }^{7}$. Ao descartar a possibilidade, o produtor indica haver a análise de uma amostra do arroz entregue à indústria, sempre por meio de mini engenhos (engenhos de provas): em relação ao engenho de prova ele não é definitivo, mas é uma ferramenta de análise do produtor. Quando há discordância em relação à classificação, as empresas classificadoras podem ser utilizadas como parâmetro. Salienta ainda nunca ter observado irregularidades junto a Josapar, especialmente pelo uso de tal mecanismo de prova:

Normalmente uso a própria corretora para avaliar a classificação. Também uso, se for necessário, o mini engenho da Josapar. Eu também tenho um mini engenho. Se ocorrer a divergência, posso usar ainda um avaliador externo que analisa o arroz, daí tenho uma nova classificação, tipo auditoria. (...). Se fosse o caso, de a gente não se acertar, bastaria eu não descarregar o caminhão (entrevista com produtor rural).

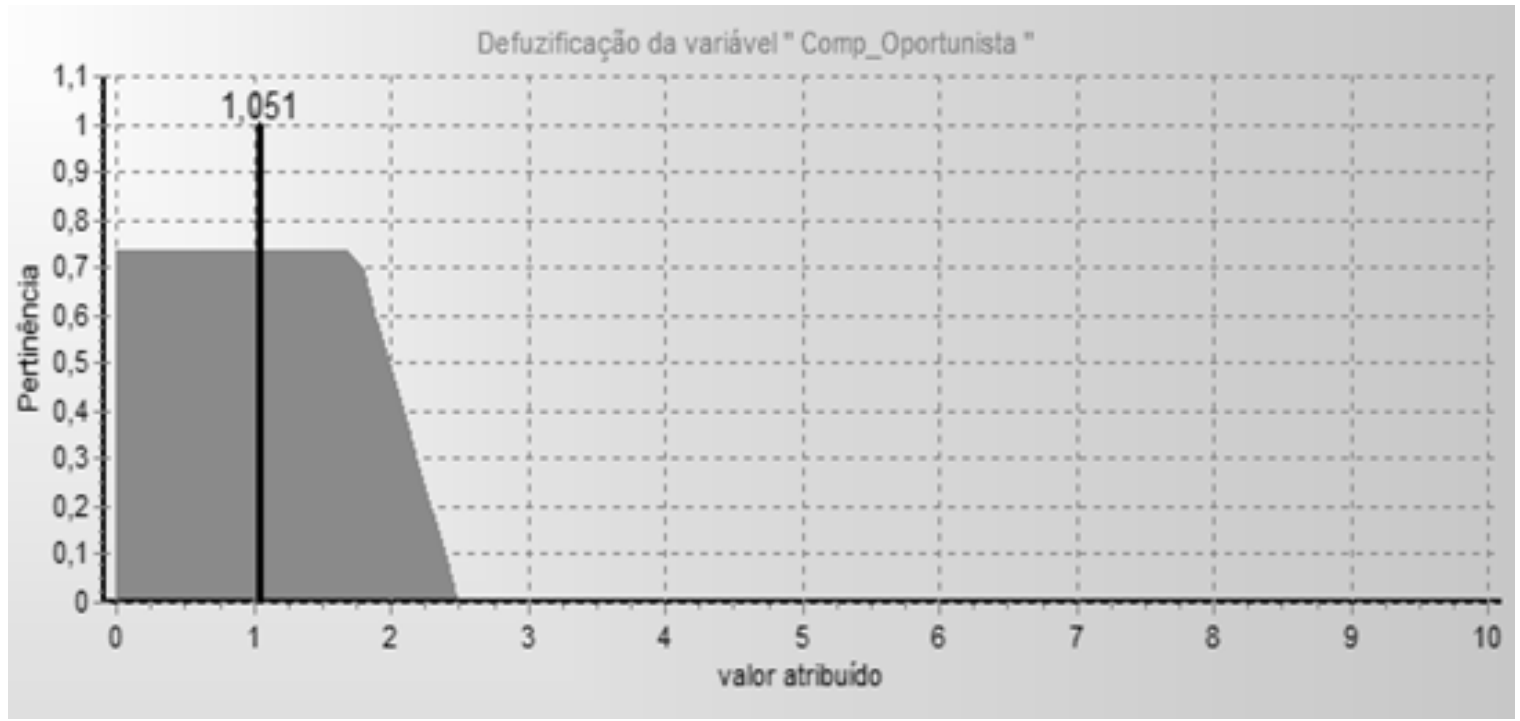

FIGURA 3 - Conjunto Fuzzy: PA Arroz - segunda sequência de dados

Fonte: dados da pesquisa

${ }^{6}$ É muito importante observar que, embora o resultado por centroide deste conjunto seja distinto dos anteriores, a saída fuzzy não significa menor comportamento oportunista. Assim, embora com valores diferentes, a interpretação correta é de comportamento oportunista "muito baixo" ou insignificante para o caso analisado.

${ }^{7}$ O termo Marreta ou marretinha é utilizado no setor para designar a "classificação não criteriosa do produto", ou seja, baseada na experiência do observador e sem a adoção de critérios seguros como os auferidos pelo engenho de prova. A referida expressão, no entanto, não é utilizada na unidade industrial de Itaqui.

Organizações Rurais \& Agroindustriais, Lavras, v. 21, n. 1-3, p. 20-35, 2019 
No que se refere ao pagamento, relata ter conhecimento de casos isolados sem, no entanto, estarem vinculados à Josapar. Os referidos casos são apontados como particularmente vinculados a arrozeiros que, no passado, enfrentaram problemas financeiros e faliram. Em negócios com a Josapar, segundo sua interpretação, os pagamentos são garantidos e depositados em no máximo 48 horas após $\mathrm{o}$ acerto (com a respectiva entrega do produto), pois se trata de uma empresa séria. Em outro depoimento, a Josapar é considerada como um parâmetro de indústria: não tenho problemas quanto à classificação do produto e, como não tenho silo, sempre deposito na Josapar e pago 8\% pela secagem. A Josapar é séria, é um parâmetro. O produtor informou ainda que, com frequência, distribui amostras do produto entre algumas indústrias. Esta forma de precaução permite a comparação da classificação. Nestes casos, não observa divergências significativas porque o uso do engenho de prova é suficiente para conter fraudes, especialmente quando relacionadas aos índices de impurezas: Eu não tenho engenho de prova, mas acho que vou comprar; ele custa uns $R \$ 13.000,00$. Já usei o engenho de prova da Josapar mesmo, mas posso usar de qualquer um se precisar.

A medição das características do produto a ser comercializado não se demonstra, portanto, um problema concreto para aqueles agentes. Além do uso dos engenhos de prova, em uma das entrevistas foi mencionada a possibilidade de recurso junto ao Serviço de Classificação Vegetal
- SERCLAVE para casos de divergência ou irregularidade na classificação do arroz. A referida empresa está sediada no município de Pelotas e presta serviços de certificação e classificação do arroz desde 2001. Em outro depoimento, além da SERCLAVE, a Ascar-Emater foi mencionada.

Em um dos depoimentos, o produtor relata seu conhecimento sobre as propriedades do produto detalhando-as: os itens mais analisados são umidade, impureza, manchados/picados, gessados e arroz preto e vermelho. Registros significativos de irregularidades quanto ao pagamento não foram encontrados. Resultados da análise fuzzy estão abaixo dispostos na Tabela 2. Os registros revelam a visão dos 5 produtores rurais (PR), em diferentes sequências de dados.

A classificação obtida na análise dos dados é para todos os entrevistados e em diferentes sequências, a de que o comportamento oportunista da Josapar é muito baixo. Assim, os arrozeiros consideram que a indústria Josapar é confiável. Ademais, possuem boas referências da companhia e não adotam salvaguardas expressivas ao realizarem negócios com ela. A Figura 4 ilustra o conjunto fuzzy de centroide de 0,995.

A uniformidade dos dados é evidente. Em consequência, sua correspondência com a análise qualitativa do estudo de caso é amplamente observada. Assim, pelos resultados obtidos, não há como sugerir irregularidades ou fraudes significativas para o setor.

TABELA 2 - Valores atribuídos às diferentes categorias - visão do produtor rural

\begin{tabular}{cccccc}
\hline Tipo & Confiança & Referências & Precaução & Saídas $\boldsymbol{F u z z y}$ & Comportamento Oportunista \\
\hline \multirow{2}{*}{ PR 1 } & 9,00 & 9,00 & 0,10 & 0,995 & Muito Baixo \\
& 9,00 & 9,00 & 1,90 & 0,995 & Muito Baixo \\
PR 2 & 10,00 & 10,00 & 0,00 & 0,995 & Muito Baixo \\
& 10,00 & 10,00 & 0,00 & 0,995 & Muito Baixo \\
PR 3 & 10,00 & 10,00 & 0,00 & 0,995 & Muito Baixo \\
& 10,00 & 10,00 & 3,10 & 1,009 & Muito Baixo \\
PR 4 & 10,00 & 10,00 & 0,00 & 0,995 & Muito Baixo \\
& 10,00 & 10,00 & 0,00 & 0,995 & Muito Baixo \\
PR 5 & 10,00 & 10,00 & 0,70 & 0,995 & Muito Baixo \\
& 10,00 & 10,00 & 1,20 & 0,995 & Muito Baixo \\
\hline
\end{tabular}

Fonte: dados primários da pesquisa 


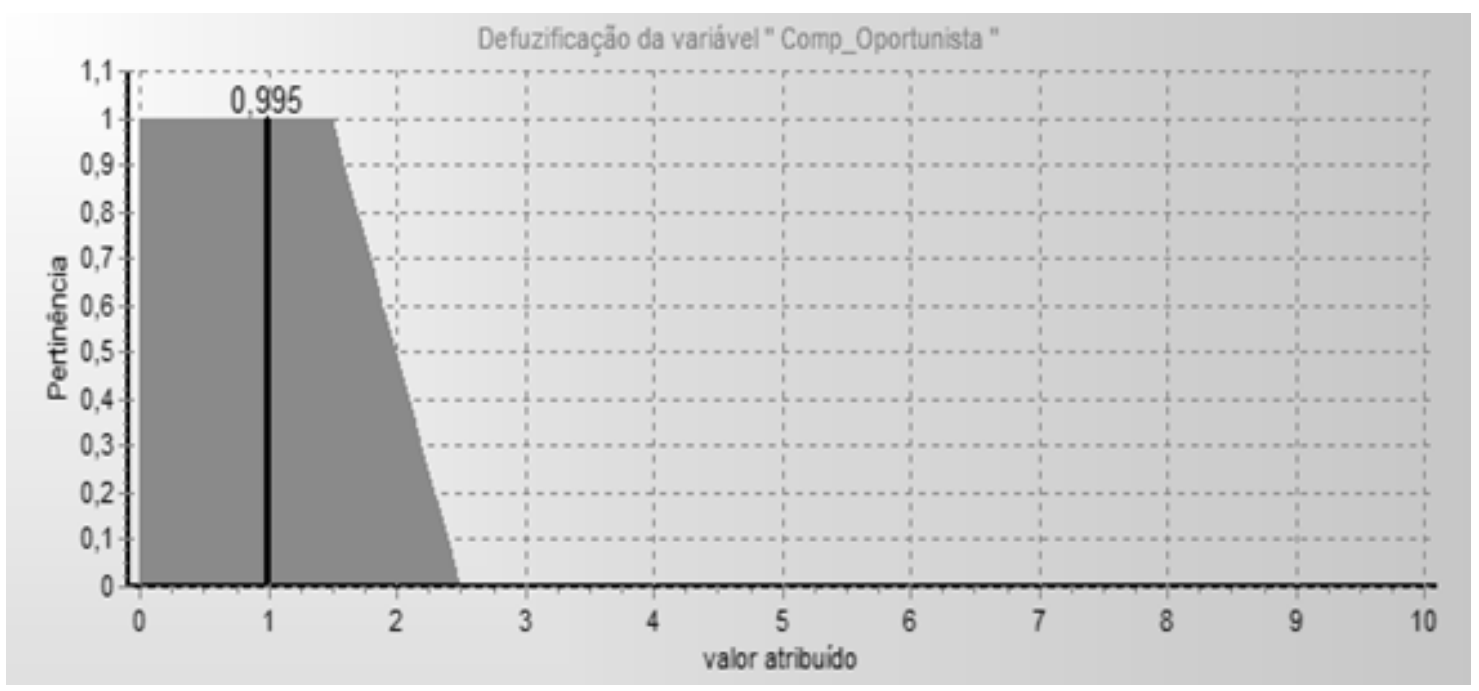

FIGURA 4 - Conjunto Fuzzy: PR Arroz - saída menor

Fonte: dados da pesquisa

\section{CONSIDERAÇÕES FINAIS}

O comportamento oportunista presente em contratos agroindustriais, aqui analisado, representa importante tema de pesquisa. A complexidade desta temática pode ser realçada igualmente por meio de um achado de pesquisa: o uso de um ativo particular, denominado engenho de prova. O engenho de prova ou mini engenho é de um equipamento relativamente simples. Sua utilidade principal está na simulação de qualidade e rentabilidade que permite testar e antever resultados. A despeito de sua simplicidade funcional, este ativo assume propriedades intrigantes do ponto de vista da transação, razão pela qual uma digressão mostra-se aqui importante. Trata-se de um ativo específico em relacionamento? Produtores e indústrias utilizam-se de forma recorrente dos mini engenhos, no entanto, seu enquadramento como ativo específico em relacionamento não é uma tarefa fácil e usual. Por definição, um ativo especifico em relacionamento é um investimento realizado para sustentar uma determinada transação particular. Neste sentido, relaciona-se em tese com as especificidades físicas, de localização, dedicada e humana que apoiam aquela transação dita particular e específica. O uso dos engenhos de prova apoia as transações, o que se comprova facilmente pela observação de seu uso entre os agentes; no entanto, ele (o engenho de prova) não responde direta e unicamente por nenhuma das especificidades usualmente citadas pela literatura. Ao contrário, este ativo responde por uma especificidade muito particular, a de avaliação ou, como indicado por sua denominação, uma especificidade "de prova". Os agentes entrevistados no presente caso reportam-se ao emprego do ativo como forma de dirimir posturas oportunistas. Em outros casos, realizam as transações sem a utilização do ativo. Assim, por este caso particular, fica clara a noção de que o ativo comporta propriedades ativas de resolução de conflitos e de resguardo diante de ameaças oportunistas.

Outro elemento caracterizador dos ativos específicos trata-se de seu baixo uso alternativo. Em tese, um ativo específico em relacionamento, perde valor quando realocado em outra transação (com outro agente), sobretudo pelo fato de que sua produtividade é afetada e um custo extra de adaptação apresenta-se. Engenhos de prova não apresentam tal característica. Os dados coletados indicam seu uso em diferentes transações sem perda de valor. Com a finalidade de se resguardarem de ações oportunistas, usos alternativos se apresentam. Entre os casos anotados tem-se: os agentes (a) adquiriram o equipamento, (b) emprestam-no para outros agentes, (c) utilizam o equipamento da própria indústria ou(d) recorreram a entidades do setor que prestam tal serviço. Pelas razões expostas, o engenho de prova não pode ser plenamente caracterizado como um ativo específico em relacionamento. Não obstante, assume a propriedade de sustentar transações entre agentes para diversificadas transações. Esta propriedade está profundamente associada ao comportamento oportunista dos agentes e, portanto, não pode ser desconsiderada na análise. Assim, a dificuldade de considerá-lo como um ativo específico ou de uso geral (não-específico), não impede de 
percebê-lo em sua capacidade de abreviar o oportunismo, de proteger a relação da assimetria de informações, enfim, de dirimir conflitos de natureza comportamental. Esta característica parece estar presente naqueles acordos, comprovando a presença de uma especificidade que não pode ser desconsiderada: a especificidade de prova.

O caso em análise apresenta grande estabilidade do ponto de vista da execução das transações. Nelas, contratos simplificados e informais são conduzidos pelos agentes no processo de compra e venda do produto. A padronização parece ser uma característica daquele setor, notadamente quanto às formas de negociação e, de certo modo, quanto ao produto. A especificidade de ativos não está contemplada naquela transação, tampouco a alta frequência. Assim, pelos contornos que assumem, os contratos associam-se fortemente ao modelo de contrato clássico, regulado via mercado (spot). Observa-se a presença de financiamento da produção em alguns casos. Embora não seja concreta a integração produtiva, sua existência implica em uma possibilidade de reorganização do setor. Deste modo, ativos específicos entrariam em cena, mudando o cenário produtivo observado.

Os riscos em termos de oportunismo estão relacionados à classificação do produto e ao pagamento. Estes dois elementos, no entanto, não apresentaram comportamento oportunista que valha registro. Sendo ínfima a presença de ações oportunistas, a importância dada pelos agentes à adoção de salvaguardas é igualmente muito baixa. A este respeito, os resultados da análise fuzzy corroboram a crença dos agentes em suas contrapartes negociais, sobretudo quanto à confiança que demonstram possuir nos agentes do setor.

Especificamente quanto à indústria, percebe-se o uso de salvaguardas nos casos em que o financiamento é utilizado. Nos demais casos, a confiança nas transações com corretores e produtores é extremamente alta, dispensando a formulação de precauções. Resultados muito semelhantes foram encontrados nas entrevistas com os arrozeiros.

Diante dos resultados encontrados, verifica-se que a contratação do setor apresenta elementos de conformidade com a tipologia de um contrato clássico. Por outro lado, o pressuposto comportamental do oportunismo dos agentes mostra-se muito baixo em ambos os planos de investigação. Ressalta-se aqui, a existência de coespecificidade de avaliação e de prova, própria do uso de ativos não específicos (de uso geral). Esta representa uma contribuição adicional importante em termos teóricos e empíricos de análise. Ressalta-se, por fim, a importância de investigações científicas que colaborem com a interpretação das temáticas agroindustriais; temas estes de complexidade e importância inquestionáveis.

\section{REFERÊNCIAS}

BARIN, A. et al. Seleção de fontes alternativas de geração distribuída utilizando uma análise multicriterial baseada no método AHP e na lógica fuzzy. Revista Controle \& Automação, [Campinas] v. 21, n. 5, p. 477-486, set./out. 2010.

BESANKO, D. et al. A economia da estratégia. Porto Alegre: Bookman, 2006.

Brousseau, E.; Glachant, J. M. (eds.) New institutional economics: a guidebook. Cambridge University Press: New York, 2008.

CALEMAN, S. M. de Q.; SPROSSER, L. R.; ZYLBERSTAJN, D. Custos de mensuração e governança no agronegócio: um estudo de casos múltiplos no sistema agroindustrial da carne bovina. Organizações Rurais \& Agroindustriais, Lavras, v. 10, n. 3, p. 359-375, 2011.

COASE, R. H. The nature of the firm. Economica, New Series, v. 5, n. 16, p. 386-405, 1937.

COSTA JÚNIOR, G. Efeito de bioestimulante, pyraclostrobina, inibidor da nitrificação e parcelamento de nitrogênio em arroz de terras altas. 2014. $76 \mathrm{f}$. Dissertação (Mestrado em Fitotecnia), Universidade Federal de Lavras, Lavras, 2014.

CReswell, J. W.; ClarK, V. L. P. Pesquisa de métodos mistos. 2. ed. Porto Alegre: Penso, 2013.

FLICK, U. Introdução à pesquisa qualitativa. Porto Alegre: Artmed, 2009.

GOMIDE, F. C.; GUDWIN, R. R.; TANSCHEIT, R. Conceitos fundamentais da teoria de conjuntos fuzzy, lógica fuzzy e aplicações. In: International Fuzzy Systems Association World Congress, 6, 1995, São Paulo. Proceedings... 1995. p. 1-38.

INSTITUTO RIO-GRANDENSE DO ARROZ. Ranking beneficiamento por produto 2014. Disponível em: http:// www.irga.rs.gov.br/conteudo/4684/mercado. Acesso em: 10 abr. 2015.

JOSAPAR. Sítio institucional. Disponível em: http:// josapar.com.br. Acesso em: 7 abr. 2015. 
LUMINEAU, F.; OLIVEIRA, N. (2020). Reinvigorating the study of opportunism in supply chain management. Journal of Supply Chain Management, v. 56, n. 1, p. 73-87, 2020.

MACNEIL, I. R. Contracts: adjustments of long-term economic relations under classical, neoclassical, and relational contract law. Northwestern University Law Review, v. 72, n. 6, p. 854-906, 1978. 2009.

. O novo contrato social. Rio de Janeiro: Elsevier,

MAGNAGO, K. F. Abordagem fuzzy em modelos populacionais discretos: metapopulação de moscas varejeiras. 2005. 189 f. Tese (Doutorado em Matemática Aplicada) Universidade Estadual de Campinas, Campinas, 2005.

MARQUES JÚNIOR, L.; PORTO JÚNIOR, S. O método da teoria neoclássica: a economia neoclássica é uma teoria refutável? In: CORAZZA, G. (Org.). Métodos da Ciência Econômica. Porto Alegre: Ed. da UFRGS, 2003.

MARRO, A. et al. Lógica fuzzy: conceitos e aplicações. Departamento de Informática e Matemática Aplicada (DIMAp). Natal: Universidade Federal do Rio Grande do Norte, 2010.

MÉNARD, C. The economics of hybrid organizations. Journal of Institutional and Theoretical Economics, Bisingen, v. 160, n. 3, p. 345-376, 2004.

NIESTEN, E.; JOLINK, A. Incentives, opportunism and behavioral uncertainty in electricity industries. Journal of Business Research, Atlanta, v. 65, n. 7, p. 1031-1039, 2012.

NORTH, D. Institutions, institutional change and economic performance. The United Kingdom: Cambridge University Press, 1990.

OLIVEIRA, S. V. de. Arranjos de coordenação em cadeias produtivas agroindustriais: contribuições analíticas com base na abordagem fuzzy. 2014. $251 \mathrm{f}$. Tese (Doutorado em Agronegócios) - Universidade Federal do Rio Grande do Sul, Porto Alegre, 2014.

ORTEGA, N. R. S. Aplicação da teoria de conjuntos fuzzy a problemas da biomedicina. 2001. $166 \mathrm{f}$. Tese (Doutorado em Ciências) - Universidade de São Paulo, São Paulo, 2001.
POSSELT, E. L.; FROZZA, R.; MOLZ, R. F. Software Infuzzy. 2011. Programa de Mestrado em Sistemas e Processos Industriais PPGSPI. Universidade de Santa Cruz do Sul, Santa Cruz do Sul, 2011.

POUPART, J. et al. A pesquisa qualitativa: enfoques epistemológicos e metodológicos. Rio de Janeiro: Vozes, 2010.

REYS, M. A.; ARBAGE, A. P.; OLIVEIRA, S. V. Identification of sources of transaction costs: a fuzzy approach for the evaluation of analytical categories. Organizações Rurais \& Agroindustriais, Lavras, v. 12, n. 1, p.11-19, 2011.

SOPEÑA; M.; ALMEIDA, F. Estruturas de governança no setor de transporte rodoviário de cargas: o caso dos portos secos no Rio Grande do Sul. Gestão \& Regionalidade, São Caetano do Sul, v. 30, n. 89, p. 20-34, mai./ago. 2014.

VELLASCO, M. M. B. R Lógica nebulosa. Núcleo de Pesquisa em Inteligência Computacional Aplicada, Curso de Engenharia Elétrica, PUC, Rio de Janeiro, 1999.

WILLIAMSON, Oliver. Por que direito, economia e organizações. Direito e economia: análise econômica do direito e das organizações. Rio de Janeiro: Elsevier, p. 16-59, 2005.

WILLIAMSON, O. E. Markets and hierarchies: analysis and antitrust implications. New York: Macmillan, 1975.

Opportunism and its critics. Managerial and Decision Economics, Lakeland, v. 14, n. 2, p. 97-107, 1993.

. As instituições econômicas do capitalismo: firmas,

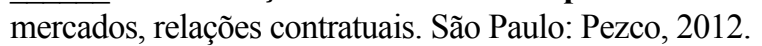

WILLIAMSON, Oliver. Selectivity contract. Destinatário: Mauro Barcellos Sopeña. Santa Maria. 19 de mai 2013. E-mail.

YIN, R. K. Estudo de caso: planejamento e métodos. Porto Alegre: Bookman, 2010.

ZYLBERSZTAJN, D. Estrutura de governança e coordenação do agribusiness: uma aplicação da nova economia das instituições. 1995. 241 f. Tese (Doutorado em Livre Docência)-Universidade de São Paulo, São Paulo, 1995.

ZYLBERSZTAJN, D.; SZTAJN, R. (orgs.). Direito e economia: uma análise econômica do direito e das organizações. Rio de Janeiro: Campus, 2005. 